\title{
SOBRE VLOG, YOUTUBE E O TELEVISIVO: MAPEANDO MODOS DE DEFINIÇÃO
}

\author{
About vlog, YouTube and the television: mapping modes of definition
}

Acerca de vlog, YouTube y TV: mapeo modos de definición

Juliana Freire Gutmann

Professora e pesquisadora/ PósCom UFBA

jugutmann@gmail.com

Fernanda Gonçalves Caldas

Mestre pelo PósCom UFBA

fernandacaldas4@gmail.com

\section{Resumo}

Empreende-se reflexão diacrônica dos modos de definição do vlog e do YouTube e suas relações com o televisivo, a fim de compreender transformações do audiovisual no contexto digital. Acepções sobre vlog e YouTube difundidas, principalmente, na imprensa nacional são mapeadas e analisadas em conjunto com a observação de características de duas produções dessas ambiências. Tal esforço de historicizar discursos identifica a TV como matriz midiática desse audiovisual. $\mathrm{O}$ estudo aborda a tecnologia como forma cultural, assumindo olhar histórico e contextual sobre o fenômeno, e adota a noção de tecnicidade como dimensão perceptiva da experiência social.

Palavras-chave: YouTube. Vlog. Modos de definição.

\begin{abstract}
It presents a diachronic reflection on the modes of definition of vlog and YouTube and their relations with $\mathrm{TV}$, in order to understand audiovisual transformations in the digital context. Conceptions about vlogs and YouTube reported mainly in the national press are mapped and analyzed together with the observation of characteristics of two productions in these environments. The effort to historicize discourses identifies TV as a media matrix for the formation of this audiovisual. The study approaches technology as a cultural form, assuming a historical and contextual view on the phenomenon, and it adopts the notion of technicity as a dimension of social experience.
\end{abstract}

Key words: YouTube. Vlog. Modes of definition. 


\section{Resumen}

El artículo realiza una reflexión diacrónica sobre los modos de definición de vlog, de YouTube y su relación con la televisión para comprender las transformaciones audiovisuales en contextos digitales. Se mapean y analizan conceptos sobre vlogs y YouTube reportados principalmente en la prensa nacional junto con la observación de características de dos producciones de estos entornos. Tal esfuerzo por historizar estos discursos identifica a la televisión como una matriz mediática para la formación de este audiovisual. El estudio aborda la tecnología como una forma cultural, asumiendo una visión histórica y contextual del fenómeno, y adopta la noción de tecnicidad como una dimensión perceptiva de la experiencia social.

Palabras clave: YouTube. Vlog. Modos de definición.

\section{INTRODUÇÃ̃O ${ }^{1}$}

"Revolução digital" (BURGESS e GREEN, 2009) e "democracia digital" (GROSSMAN, 2006) são formulações comumente atribuídas a uma espécie de consequência da tecnologia nos atuais contextos comunicacionais. Tal abordagem se pauta, muitas vezes, no caráter "inovador" da técnica e numa relação quase que causal com o que tem sido denominado de "cultura participativa" (JENKINS, 2009). Tendo como objeto de interesse os modos de definição do audiovisual relacionados ao vlog e ao YouTube no Brasil, este artigo parte de constatação semelhante sobre a centralidade da cultura digital na experiência comunicacional contemporânea, mas se afasta do que considera uma concepção instrumentalista da questão. Entendemos que o caráter transformador (e não necessariamente inovador) desse audiovisual passa por relações entre tecnologia, cultura e a sociedade, e que a produção de conhecimento sobre o fenômeno demanda esforço de historicização.

Neste artigo, apresentamos resultados de análise diacrônica sobre sentidos relacionados ao vlog e ao YouTube, com objetivo de compreender matrizes midiáticas que caracterizam essa forma audiovisual e se mostram interligadas, sobretudo, a lógicas televisivas. Partindo da premissa de que elementos considerados "novos" atuam como dimensão de reconhecimento do presente porque orbitam numa trama de distintas temporalidades, a investigação é mobilizada pela seguinte questão: como a TV é posicionada enquanto matriz midiática nas disputas em torno dos modos de definição do vlog e do

\footnotetext{
${ }^{1}$ Versão atualizada de paper apresentado no XXVII Encontro Anual da Compós, PUC-MG - Belo Horizonte, 2018. Artigo apresenta resultados de pesquisa com financiamento do CNPq.
} 
YouTube no Brasil? Propomos abordagem cultural e historicizada do fenômeno, buscando identificar disputas sobre tais definições por meio da análise que articule materialidades desses audiovisuais e os discursos sobre eles em circulação na imprensa, conforme proposta metodológica de Silva e Gutmann (2018), embasada na noção de formação discursiva (FOUCAULT, 2013); na reflexão histórica via ação de contextualização, nos termos de Ribeiro, Martins e Antunes (2017); e no entendimento da tecnologia enquanto tecnicidade (MARTIN-BARBERO, 2008).

O corpus reúne 22 matérias publicadas por veículos da imprensa brasileira e internacional (Veja, Isto É Gente, O Globo, O Estado de S. Paulo, Folha de S. Paulo, BBC Brasil, Terra, Time), numa busca que priorizou o período de formação da cultura audiovisual do vlog e do YouTube no país, além de duas produções audiovisuais: o Nós\&Nóis, de Thiago Fialho, "primeiro vlogueiro" reconhecido no Brasil (MACHADO; MONTEIRO, 2004; MARTINS, 2006), e o canal de Whindersson Nunes, identificado como "um dos maiores youtubers do país" (RIGA, 2019).

Ao mapear sentidos e deslocamentos de sentidos, continuidades e rupturas que dizem sobre essa forma audiovisual, observamos que a possibilidade de identificar transformações na comunicação se respalda na capacidade de compreender convenções e matrizes midiáticas. Resultados deste estudo indicam a televisão enquanto referência da formação do audiovisual em contextos digitais.

\section{ABORDAGEM CONTEXTUAL E MODOS DE DEFINIÇÃO}

Entendemos o investimento analítico nos discursos que circulam sobre vlogs e YouTube e suas relações com o televisivo como ação de contextualização nos termos indicados por Ribeiro, Martins e Antunes (2017), quando desenvolvem reflexão acerca das historicidades no campo da comunicação com base em dois movimentos metodológicos. O primeiro, pautado no conceito de contexto, reflete sobre a necessidade dos estudos não se restringirem a aspectos históricos, sob o risco de delinear apenas uma cronologia dos meios, mas englobarem enfaticamente processos comunicacionais. O segundo é sobre a importância de enxergar os meios de comunicação como "figura" de historicidade, não se limitando a um mero pano de fundo histórico. Os autores entendem a noção de contexto enquanto heterogeneidade constitutiva, defendendo sua abordagem como prática dinâmica pela qual se considera a polifonia de vozes e o alargamento da noção de documento, visto como produto 
do jogo de forças originário de práticas sociais. Nessa perspectiva, o olhar historicizado aqui proposto não se reduz a um conjunto de fases ou episódios da história, ao contrário, busca preservar relações entre variadas temporalidades para a compreensão de como disputamos definição sobre vlog e YouTube. Ao mesmo tempo, as vozes mapeadas na imprensa, pela descrição do objeto empírico e também a partir dos referenciais acadêmicos acionados são colocadas em articulação em todo processo de análise.

Por esse entendimento, este trabalho analítico envolve articulações entre formas materiais e discursos do âmbito da produção e da recepção vistos a partir da crítica jornalística, conforme proposta de Silva e Gutmann (2018). As autoras recorrem à noção foucaultiana de formação discursiva enquanto dimensão analítica pela qual seria possível captar, na análise dos processos comunicacionais, rupturas que operam juntos com aspectos já cristalizados. Foucault (2013) sustenta que a história não se explica pela cronologia, nem por regularidades organizadas de modo progressivo e linear, mas por uma série de deslocamentos, atravessamentos e disputas. Assim, desenvolve o conceito de formação discursiva como possibilidade de descrever relações dispersas e descontínuas entre enunciados.

O interesse do autor está nos pontos de dispersões e não nas permanências ou na tentativa de destacar e isolar unidades de coerência dos conjuntos enunciativos. $O$ que Foucault parece nos apresentar é uma operação analítica para fisgar recorrências e regularidades, em termos de disputa e não de consenso, entre distintos tipos de enunciação, objetos, conceitos, temáticas e modos de definição. “As regularidades não se organizam, ao longo do tempo, de modo linear, progressivamente dedutivo e permanentemente estático, mas são construídas por atravessamentos contínuos” (SILVA; GUTMANN, 2018. p. 241).

Esses sistemas de dispersão - que aqui buscamos compreender a partir do modo como a imprensa e também o campo acadêmico caracterizam o vlog e o YouTube, tendo a TV como uma espécie de referência midiática - são mapeados pela descrição de diferentes atributos em disputa. Nos termos de Foucault (2013, p.46), pela observação de uma ordem em seus aparecimentos sucessivos, correlações entre simultaneidades, posições reconhecíveis em um certo espaço-tempo, funcionamentos recíprocos, transformações hierarquizadas. É nessa direção que pretendemos desvendar discursos e formas materiais acerca dos modos de definição do audiovisual no vlog e no YouTube, num esforço de identificar disputas que posicionam a TV como matriz, seja pelo sentido de referenciação, comparação ou distinção. 


\section{TECNOLOGIA COMO FORMA CULTURAL E SENSÍVEL}

Você. Esta foi a escolha da revista Time em sua edição anual sobre a personalidade do ano em 2006 (GROSSMAN, 2006). O pronome você (you) é estampado dentro de um monitor, e a ilustração impressa num papel laminado funciona como espelho para que o leitor se veja ali refletido (Figura 1). A escolha é motivada, segundo a revista, em razão dos espectadores "tomarem as rédeas da mídia global", "forjarem a nova democracia digital", "trabalharem de graça e superarem os profissionais em seu próprio jogo". De modo que o protagonismo do sujeito nesse espaço seria explicado pelo desejo de "se fazer ver". Tal arena de visibilidades é compreendida pela Time como "instituidora da democracia digital" e definida como "uma comunicação de todos e para todos". Seria o início de uma "revolução" que partiria de casa e democratizaria o espaço público. O YouTube nos daria, assim, a "condição de democracia" como "uma ferramenta para reunir as pequenas contribuições de milhões de pessoas e torná-las importantes", dando igual relevância, conforme a revista, a registros diversos: "o bêbado na festa", o "projeto de ciência da escola", "as confidências e solos de guitarra" (GROSSMAN, 2006).

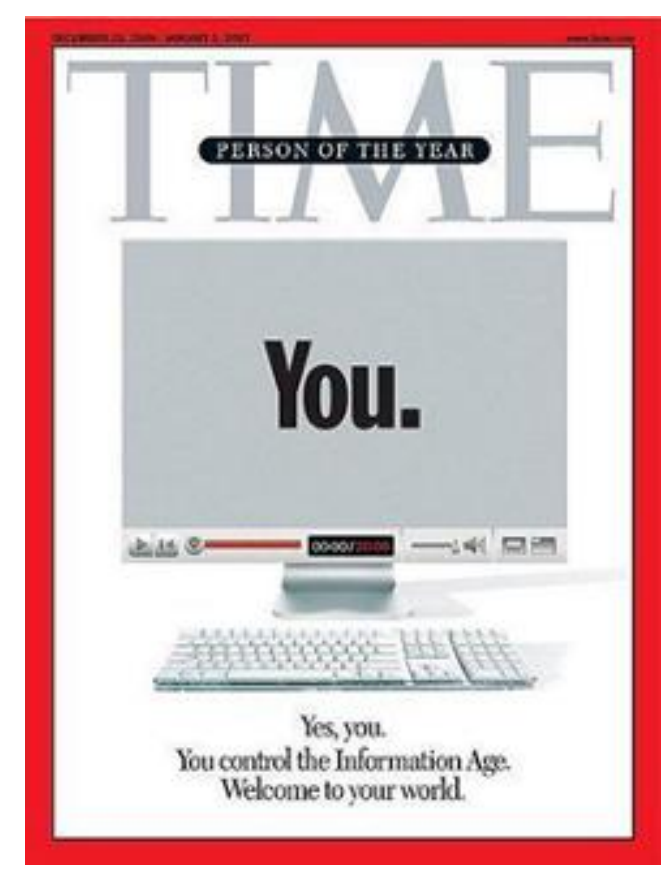

Figura 1 - Capa da revista Time de dezembro de 2006 Fonte: GROSSMAN (2006) 
No campo acadêmico, Burgess e Green (2009) desenvolvem abordagem sobre o YouTube centrada na relação entre os artefatos técnicos da plataforma e o surgimento daquilo que Jenkins define como "mídia participativa", marcada pelo fato de os consumidores e produtores de mídia não ocuparem mais papéis separados, mas se apresentarem como "participantes interagindo" (JENKINS, 2009, p. 30). As "novas" formas de participação social seriam, então, possibilitadas pela existência de "novos" artefatos técnicos - câmera digital, software de edição e conexão.

Internet e YouTube são colocados numa posição de protagonistas da sociedade com base numa repetição de premissas revolucionárias que também ancoraram abordagens sobre o surgimento do rádio, do cinema, do automóvel, das máquinas de guerra, quando vistos enquanto "aparatos". Premissas que parecem afirmar, pela ênfase instrumentalista, a separação entre sociedade e tecnologia, reduzindo a primeira a uma formação originária da segunda ou efeito dela. O tom "revolucionário" dado ao fenômeno, que encontra justificativa no chamado "caráter inovador" da técnica, também reforça uma espécie de "tabula rasa do tempo. Nada existia antes do novo e nada existirá depois, senão ele mesmo" (FELINTO, 2011, p. 44).

Especificamente sobre a obra de Burgess e Green (2009), Felinto critica o apagamento histórico presente já no título "YouTube e a Revolução Digital: como o maior fenômeno da cultura participativa está transformando a mídia e a sociedade”. O autor salienta o incômodo com o "tom professoral" do uso do termo "como", responsável por colocar "o leitor num banco escolar à espera de ser instruído nos mistérios das profundas transformações tecnológicas e sociais que se desdobram à sua frente" (FELINTO, 2011, p. 44-45). Também critica o acento dado ao sentido de "revolução", que reforça o imperativo do presente por negação ao passado: "não basta ser novo: é necessário fazer política de terra arrasada com o passado" (FELINTO, 2011, p. 45)

Em acordo com a crítica de Felinto (2011), propomos uma abordagem sobre o YouTube, nos termos de uma tecnologia, assentada nos estudos da cultura e do sensível, numa defesa de que, mais que uma ferramenta ou simples artefato técnico, ela é uma forma cultural (WILLIAMS, 2016). Conforme Williams (2007), o termo "tecnologia", desde o século XVII, era interpretado como estudo sistemático de uma arte, a partir do século XVIII, aparece como "descrição das artes, especialmente as mecânicas”, já no século seguinte, alcança o entendimento de "artes práticas" (2007, p.392). Em seu sentido moderno, segundo o autor, é atrelado à aplicação prática do conhecimento num determinado campo, resultado ou 
produto do desenvolvimento das Ciências, o que influencia a abordagem dos meios de comunicação como tecnologia dissociada das forças da sociedade. Ao contrário dessa visão, Williams (2016) sustenta que, mais do que um projeto autônomo, a tecnologia é definida por questões sociais e culturais. O autor reconhece o papel das grandes corporações no seu desenvolvimento técnico, mas desloca sua acepção "das propriedades fixadas do meio de comunicação" (WILLIAMS, 2016, p.143). Quando reflete sobre a televisão, a posiciona não como aparato de engenharia, mas resposta a um conjunto de necessidades sociais, políticas e econômicas, portanto, uma forma cultural.

Assim, é fundamental a este trabalho a compreensão da tecnologia de modo imbricado à cultura, à sociedade e às sensibilidades. Recorremos à acepção da tecnologia, nos termos originários de Walter Benjamin (1987), como dimensão de constituição do sensorium da experiência; como lugar de tensão entre "reprodutibilidade técnica" (ou, num sentido mais atual e vulgar, "desenvolvimento tecnológico") e modos de fazer e sentir. É por essa lógica que Jesús Martín-Barbero compreende a tecnologia enquanto reorganizadora perceptiva da experiência social. Benjamin é assumido pelo autor como referência central para abordar a tecnologia, sob o argumento de que esboça "algumas chaves para pensar o não-pensado: o popular na cultura não como negação, mas como experiência e produção" (MARTíNBARBERO, 2008, p. 72). Pela noção de mediação cultural, tão cara ao pensamento de Martín-Barbero, vislumbra-se a possibilidade de compreender historicamente transformações nas condições de produção e nos espaços da cultura que vão implicar em mudanças do sensorium. Quando a TV é seu objeto de investigação, o autor utiliza o mesmo argumento de Benjamim a propósito da fotografia: "é a própria noção de cultura, sua significação social, que está sendo transformada pelo que a televisão produz e em seu modo de reprodução" (MARTÍN-BARBERO, 2008, p. 300).

Presume-se, então, que tecnologias de comunicação estimulam as formas pelas quais enxergamos e experimentamos o mundo, mas também são produtos do mundo. É nessa direção que Martín-Barbero (2008) encontra no sentido de tecnicidade um lugar teórico para pensar competências de linguagem, materialidades, discursos e modos de uso que envolvem a tecnologia. A tecnicidade é mediação cultural, um processo estruturante que envolve lógicas de produção e de consumo articuladas pela vida cotidiana e pelos dispositivos tecnológicos e discursivos da mídia (LOPES, 2014, p. 71).

A compreensão das tecnicidades e das mudanças do sensorium implicam uma ação analítica em direção às articulações entre processos de modernidade e tradição (MARTIN- 
BARBERO, 1995). O autor dá relevo à atuação das matrizes culturais para a análise das formas constituidoras do "presente". As matrizes nos dão importantes pistas para ver transformação nos meios e suas formas de expressão (MARTIN-BARBERO, 2008). Assim, defendemos o movimento analítico na direção da historicização das formas e discursos que envolvem o vlog e o YouTube, pois entendemos que a apreensão dos aspectos transformadores do audiovisual nas ambiências digitais passa, à princípio, pelo modo como ali também atuam apropriações e reapropriações de matrizes culturais midiáticas. A televisão é uma delas.

\section{VLOG: A TV AMADORA NA WEB}

As primeiras notícias relacionadas aos vlogs aparecem na imprensa brasileira restritas às colunas de tecnologia dos veículos impressos. Seus modos de definição tinham o blog como referência: "terceira geração dos blogs" (MONZILLO, 2004), "blogues com vídeos digitais" (BARRETO, 2004), "diários virtuais que oferecem vídeos e fotos" (BLOGUE, 2004). As abordagens assinalam o sentido de "diário" que tinha "vídeos" como elemento diferenciador (MONZILLO, 2004). Os termos utilizados para denominar a prática também acentuavam a referência ao blog (vblog, vogs, videoblogues, vlogs), agora enquadrado como “diário em vídeo online” (BARRETO, 2004; MONZILLO, 2004; MARTINS, 2006; MONTEIRO, 2006).

A princípio, o termo "vlogueiro" ou "vídeo blogueiro" fazia referência ao fato de uma "pessoa comum" disponibilizar vídeos na internet. O vlog era assim associado a uma "nova prática" de contar histórias da vida privada pelo uso do audiovisual. No Brasil, as primeiras notícias sobre vlog tinham a figura do "usuário", termo dado aos sujeitos que "fazem uso" da internet, como principal interlocutor e priorizavam enquadramentos sobre requisitos técnicos, entre eles: 1. as possibilidades de uso de câmeras digitais amadoras, telefones celulares e webcams para "produzir filmes de curta duração e publicá-los em um videoblogue" (PREÇOS, 2004); 2. os formatos mais eficientes de exibição de vídeos na internet (PREÇOS, 2004); 3. os serviços de hospedagem dos sites (BARRETO, 2004); 4. o "crescimento lento" (BOXER, 2005) creditado, quase sempre, “à limitação tecnológica dos internautas" (MONZILLO, 2004); 5. os altos custos da banda larga no Brasil, que prejudicavam o acesso à internet; e 6. o uso de rede de telefonia que dificultava o upload, download e as visualizações de vídeos (MONTEIRO, 2006). 
A partir do ano de 2005, começamos a identificar os termos "mania" e "febre" (BOXER, 2005; MONTEIRO, 2006) para caracterizar o "fenômeno de proliferação de vídeos na internet" (MONTEIRO, 2006), que tinha o "registro do cotidiano" como característica central (BOXER, 2005). É quando a proximidade do vlog com a televisão é convocada de modo mais enfático pela imprensa. Em agosto de 2005, reportagem do New York Times sobre os vlogs, reproduzida pelo jornal O Globo, é ilustrada com a imagem de uma câmera da Canon que lançava, na época, a primeira máquina com gravação em DVD, o que reforça a proeminência do "registro amador" como "nova" forma audiovisual. Ao mesmo tempo, a reportagem traz a TV como dimensão de definição dos vlogs. "Os vlogueiros não conseguem chegar a um acordo do que são de fato os vlogs", porém, "o recém-nascido já parece ter escolhido sua companheira. Parabéns, é a televisão" (BOXER, 2005).

Os modos de feitura eram então explicados pelo reconhecimento de funções e formas específicas associadas à TV: "sites mostram vida de criadores, trazem clipes musicais e vídeos de caráter jornalístico" (CONHEÇA, 2004); vlogs "se aproximam muito das funções dos meios audiovisuais (televisão e rádio)" (MONZILLO, 2004). A produção dos vlogs é associada à "responsabilidade de ter sempre uma programação fresquinha, saindo do forno" (BOXER, 2005), além da variedade temática, que abrange "programas" de culinária, minidocumentários, notícias fictícias etc., tendo como princípio mais marcante "o registro da vida comum" (BOXER, 2005). O lugar do ordinário parece se cristalizar como dimensão de reconhecimento desses vídeos e os gêneros e formatos televisivos atuam como referências de produção audiovisual. Articulados à marca autobiográfica que permeia cenários, corpos e textos, os "diários em vídeo" apresentavam diversas formas relacionadas à TV - videoclipe, reality show, esquetes de comédia, vinhetas, uso de créditos etc.

A imprensa nacional (MACHADO; MONTEIRO, 2004; MARTINS, 2006) dá o título de primeiro vlogueiro brasileiro a Thiago Fialho, com seu programa Nós\&Nóis (2003-2006). O programa era exibido na plataforma criada por Fialho ${ }^{2}$, o videolog.com.br. Em entrevista publicada pela Folha de S. Paulo (BARRETO, 2004), Fialho conta que tudo começou com um blog no qual relatava acontecimentos pessoais e de amigos. "Então pensei: 'Por que não contar tudo isso através de vídeos? Seria mais fácil descrever os fatos com imagens do que com palavras'" (BARRETO, 2004). No discurso do produtor, a periodicidade é destacada como valor, o que reforça aproximação com a temporalidade televisiva. "Já vi muitos vlogs

\footnotetext{
${ }^{2}$ Não é mais possível acessar a íntegra do Nós\&Nóis publicado no site até 2006, quando a página foi excluída da internet. Localizamos dois vídeos no YouTube, por meio do usuário truebrujah.
} 
perderem audiência porque seus donos não publicavam vídeos com frequência", afirma Fialho (MARTINS, 2006).

O Nós\&Nóis apresenta narrativas construídas em forma de videoclipe com cenas do cotidiano de amigos em clima de diversão. No trailer do programa (TRUEBUJAH, 2007), com duração de 1 minuto e 07 segundos, as cenas transitam entre espaços urbanos (ruas, um show de rock, quadra de futebol, pista de skate) e ambientes domésticos (o quarto, a piscina, a laje de uma casa). O contexto juvenil é realçado por imagens de skatistas e forte acento em um contexto musical ligado ao rock, gênero que embala a montagem do vídeo (Figura 2).

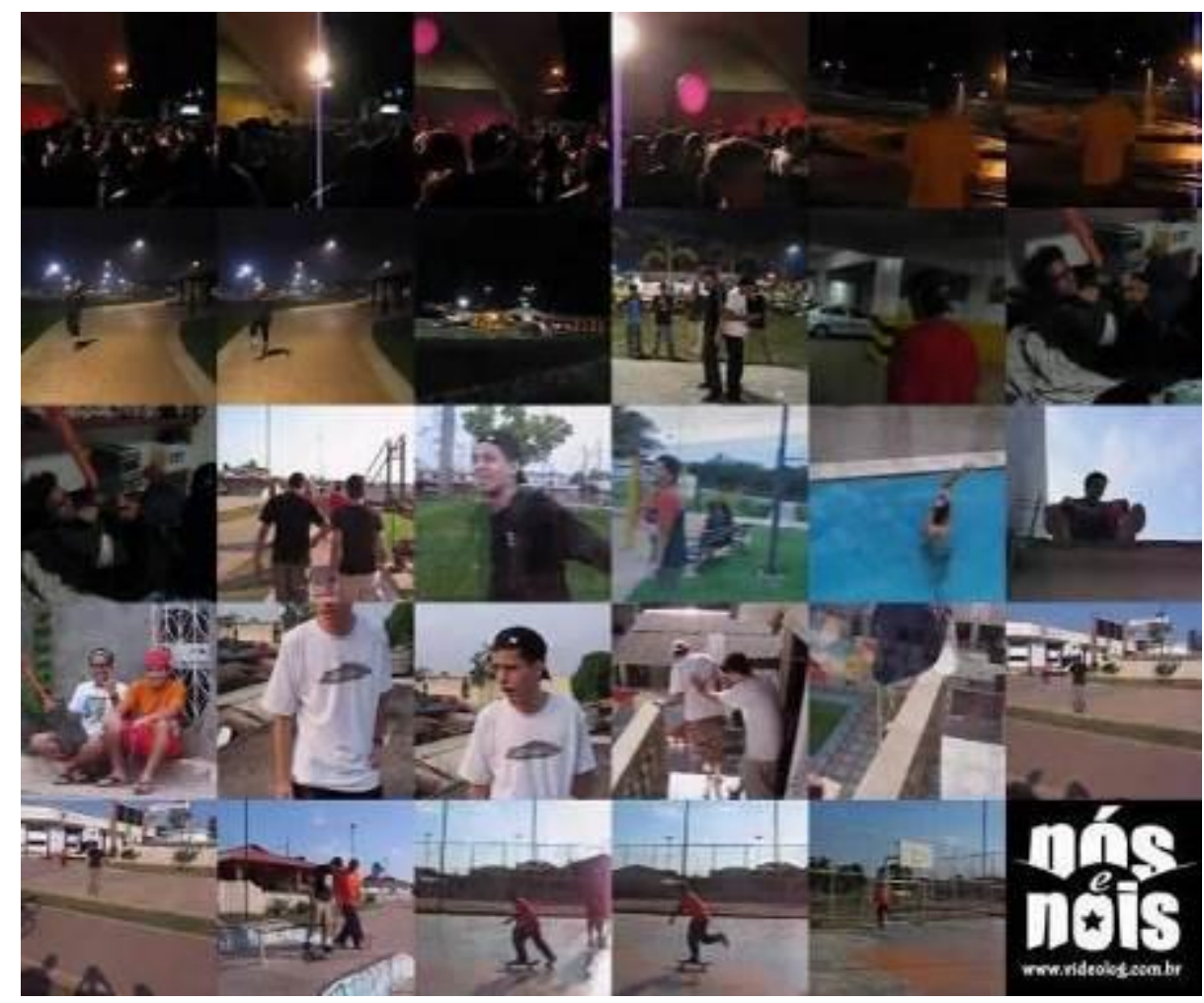

Figura 2 - frames do programa Nós \& Nóis.

Fonte: TRUEBUJAH (2007)

Estrutura amadora, viés confessional, gravação e edição executadas pelo próprio protagonista do vídeo e discurso autobiográfico foram definições sobre o vlog que se popularizaram de modo disperso na internet. Contudo, no lugar de produções caseiras com o intuito de fazer parte de um arquivo pessoal e familiar, os vlogs começam a apontar para a constituição de uma arena de disputas por visibilidades mais ampla. A TV é posicionada como referência desse modo de fazer que precisava corresponder às expectativas de audiência não mais circunscrita aos amigos e familiares. Sentidos de programação, programa, periodicidade, atualidade, gêneros e formatos televisivos constituíram referências para o que, 
a princípio, aparece como "nova prática", mas que vai se configurando enquanto forma audiovisual institucionalizada com aparecimento e ascensão do YouTube.

\section{YOUTUBE E AS CUSTOMIZAÇÕES DO TELEVISIVO}

Em 23 de abril de 2005, o YouTube apresentava o que é considerado seu primeiro vídeo, uma gravação caseira de 18 segundos feita pelo cofundador da plataforma. Em um único plano, Jawed Karim aparece em um zoológico, tendo ao fundo um elefante, e fala para a câmera sobre a grande tromba do animal. Ele finaliza seu depoimento e o vídeo abruptamente, quase que em tom irônico: “... e isso é praticamente tudo o que há para dizer” (JAWED, 2005). O site era lançado como um "experimento" de colegas de trabalho. O slogan Your Digital Video Repository (“Seu Repositório de Vídeos Digitais”, tradução nossa) evidenciava o sentido de "acervo", "repositório" de material audiovisual produzido pelo usuário, "depósito" de vídeos caseiros em forma de diários e em tom confessional. O "Quem somos" do site continha instruções vagas, mas que já explicitavam expectativas sobre seus modos de uso, reforçando marcas do vlog relacionadas aos registros do cotidiano e do ambiente privado e às formas amadoras de gravação: "Exiba seus vídeos favoritos para o mundo. Faça vídeos de seus cães, gatos e outros bichos. Publique em seu blog os vídeos que você fez com sua câmera digital ou celular. Exiba seus vídeos com segurança e privacidade aos seus amigos e familiares [...]" (BURGESS, GREEN, 2009, p. 20).

A compra pelo Google, em 2006, anuncia deslocamentos dessa ambição inicial em direção ao sentido de corporação midiática, cuja visibilidade é vendida e aferida pela quantidade de cliques, um universo promissor à publicidade e que rende monetização de acordo com as visualizações e adequação do conteúdo às políticas da plataforma. A mudança do slogan para "Broadcast Yourself” ("transmita você mesmo", tradução nossa) evoca o lugar da transmissão não simplesmente pela ideia de difusão de conteúdo. Há um forte acento no sentido de broadcast enquanto "radiodifusão", termo relacionado ao campo de atuação das grandes corporações de rádio e TV. Ao mesmo tempo, o uso da palavra yourself reforça, como traço de continuidade com o vlog, o efeito de protagonismo do sujeito consumidor/produtor, reelaborando o lugar do espectador/internauta, comumente chamado de "usuário".

Essa fusão corporativa foi fundamental para reforçar conexões ainda mais enfáticas com a televisão. Conforme Van Dijck (2013), a inserção de um dos pilares do Google, o 
mecanismo de busca, tem papel fundamental para o processo de sociabilidade em rede do audiovisual em circulação no YouTube e na TV, que tem sua produção arrastada para o ecossistema de redes sociais digitais. "A crescente interdependência entre as plataformas de compartilhamento de televisão e vídeos e a permutabilidade sem atrito dos recursos do YouTube, Facebook e Twitter, refletem e constroem simultaneamente a cultura emergente da conectividade" (VAN DIJCK, 2013, p.111).

Fazendo novamente remissão à Time, citada no segundo tópico deste artigo, é sintomático que, após eleger em 2006 "you” como personalidade do ano, em 2007, o periódico traga uma matéria intitulada The Year of Them (“o ano deles", tradução nossa) (PONIEWOZIK, 2007). "Them" em referência aos profissionais, às grandes empresas de mídia que, reconhecendo o potencial de visibilidade da internet, criou sites, blogs, canais, podcasts e vídeos, não só disputando espaço junto ao produtor ordinário, mas cooptando mesmo a sua prática. Conforme a revista, se foi o sujeito comum ("you") que fez a descoberta dos usos da web, são "eles” que sabem fazer dinheiro (PONIEWOZIK, 2007).

Assim, ganha relevo o lugar das grandes empresas de comunicação como sistema que incorpora essa forma audiovisual às lógicas do capital. A publicação da Times aconteceu apenas um mês depois do YouTube inaugurar a ferramenta Content ID, um esforço de minimizar problemas judiciais referentes à propriedade de conteúdo, a partir do reconhecimento e gerenciamento de direitos autorais, inclusive com monetização aos respectivos proprietários (YOUTUBE, 2009). Em 2007, também foi criado o programa de parceria, que remunerava produtores de conteúdos populares. Em 2012, o recurso foi ampliado a todos os criadores que alcançassem 10 mil visualizações.

As primeiras definições do YouTube na imprensa brasileira são feitas por aproximação com a ideia de TV sob demanda. O jornal O Globo apresenta a "nova plataforma" como "o serviço que mais se aproxima do conceito de televisão por assinatura, aquela na qual o telespectador monta sua grade de programação, assiste apenas ao que lhe interessa e quando quer" (MONTEIRO, 2006). Na plataforma, os canais estão expostos em forma de catálogo personalizado. A possibilidade de visualizar as diversas ofertas rememora a opção de olhar o catálogo de programação dos canais de TV pagos. O próprio modo de organização do conteúdo ancorado na ideia de "canal" (e, mais especificamente, de "canal segmentado") responde por uma ambiência de partilha de gostos e desejos que se expressam em formas audiovisuais características de uma "emissora" de TV: vinhetas, programas, apresentadores, anúncios comerciais etc. (GUTMANN, 2015). 
Assim, o termo vlog passa a concorrer com a ideia de "canal", cada vez mais naturalizado como lugar de interação em torno do audiovisual na internet. Ao analisar construções dos usuários no YouTube, Montaño (2016) identifica o "canal” como uma das molduras dada a esses sujeitos numa ressignificação aos conhecidos canais de TV. Em estudo que analisou os layouts da home do YouTube nos anos de 2010, 2012 e 2016, a autora mapeia sentidos diversos atribuídos a estes sujeitos: colecionador, flâneur, desenvolvedor e empreendedor. Apesar de não ser objetivo da sua pesquisa, o esforço em acentuar dimensões de distinção, quando identifica esse lócus próprio da plataforma, parece reforçar também marcações muitos particulares de um canal de TV: criação de conteúdo próprio, monitoramento dos seguidores e viewers (que, na tradição televisiva, se reverte nas pesquisas de IBOPE), além da opção do uso de transmissão ao vivo. As dinâmicas da televisão, mesmo enquanto dimensão residual, atravessam o que considera práticas próprias da plataforma resultantes de repetição e apropriações, os memes, os vlogs, os tutoriais, mas também as webséries, os programas de humor, as lives, os canais que atualizam a meteorologia etc.

A referência à TV, seja num sentido de semelhança ou de diferenciação, impera nas abordagens sobre o YouTube na imprensa, agora não mais restritas aos cadernos especializados. Em reportagem de capa da revista O Globo, intitulada Fala que eu te assisto (FISCHBERG, 2015, p. 22-30), quando se busca uma definição para esse tipo de usuário (que agora transita entre as denominações vlogueiros e youtubers), a matriz televisiva é acionada: "Houve uma sofisticação, hoje eles conseguem montar uma programação como a televisão" (FISCHBERG, 2015, p. 27).

Em 2006, a Veja estampa em sua capa "A revolução da TV pelo computador”, ao lado da ilustração de um controle remoto em forma de mouse (EM 2006, 2018). Na reportagem intitulada "A nova era da televisão" (Figura 3), o YouTube é descrito como "um dos mais populares sites da internet", responsável "por transformar a relação do espectador com o mundo da imagem". Autonomia e segmentação do público estimulados pela popularização das TVs pagas no país, aumento do número de acessos, os vídeos virais, muitos deles relacionados à televisão, as tecnologias móveis, a possibilidade de compartilhamento e o senso de comunidade são algumas das razões atribuídas para a defesa da tese de "uma revolução que marca o fim da TV como se conhecia até hoje" (EM 2006, 2018). Tanto as razões elencadas, quanto a descrição das produções ("filmagens históricas, trechos de seriados ou novelas, vídeos independentes, cenas caseiras de um bebê sorrindo ou de bichinhos de 
estimação") constituem ambiguidades no modo como a televisão é mobilizada enquanto referência para a compreensão dessa "nova" forma de produção e consumo audiovisual.

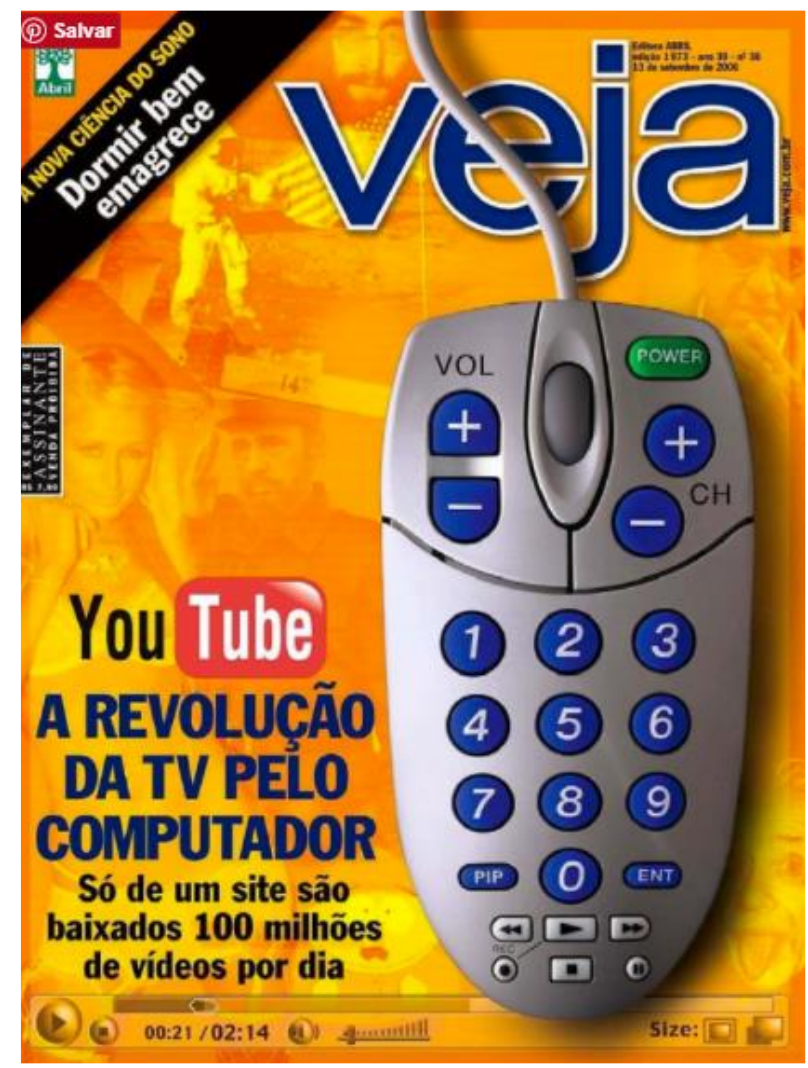

Figura 3 - Ilustração da capa da Veja de 13/09/2006. Fonte: VEJA (EM 2006, 2018).

Disputas de definição na relação com a TV aparecem em outros títulos de reportagens, como "Te vi no Youtube" (MONTEIRO, 2006) e "A televisão dos nossos tempos" (ROCHA, 2014). Em matéria de O Globo, Celestino (2006) caracteriza o YouTube como "a televisão que todos sonham”. Em reportagem de O Estado de S. Paulo (ROCHA, 2014), é definido como uma "opção de televisão", pela qual se pode assistir a "vídeos jornalísticos, documentários sobre o mundo animal, show de música, clipes de humor, até longa metragens na íntegra". A ideia de substituição da TV é uma constante. Dentre os motivos, identificamos a associação do sucesso do YouTube ao que a imprensa denomina de "vácuo deixado pela TV aberta” (FISCHBERG, 2015). Sob o argumento da ausência de conteúdo infanto juvenil na TV, a juventude teria agora "um refúgio de entretenimento" (FISCHBERG, 2015).

No tratamento dado pela imprensa, os "vloggers" amadores passam a fazer parte de uma categoria "profissional", que mesmo não sendo empregados pelo YouTube, personificam a empresa sob a alcunha de youtubers. A cobertura noticiosa começa a reposicionar as 
nomenclaturas na medida em que localiza esses sujeitos enquanto celebridades - "hoje, ser youtuber é o novo ator" (MANS; CAPELAS, 2016) - e profissionais - "escolas ensinam como se tornar um youtuber" (MANS; CAPELAS, 2016). O tom chega a ser didático: "quando eles começaram, entre 2009 e 2010, ainda eram chamados de vloggers. O termo caiu em desuso quando fazer vídeos para o YouTube se consolidou como uma forma financeiramente possível de se viver" (LARA, 2016).

O status de "celebridade" conferido aos youtubers é comumente construído pelo enquadramento do "ranking": "Whindersson Nunes e outros: as 5 estrelas do YouTube com mais seguidores no mundo" (WHINDERSSON, 2018), "Os 10 youtubers que mais ganham dinheiro" (OS 10, s/d). O lugar do ordinário, da cotidianidade, da banalidade, historicamente associados à TV e também apropriado pelo vlog, ampara boa parte das definições para os também chamados "influenciadores", mas agora simplicidade, intimidade e testemunho são postos como valores de autenticidade e distinção.

Sobre o Whindersson Nunes, visto pela imprensa como "um dos maiores youtubers do país" (RIGA, 2019), recaem definições que reforçam o "humor inocente”, "hábitos humildes", trajetória pobre como "ajudante de garçom". O youtuber piauiense se autodenomina, na descrição do seu perfil, o "Lampião do Youtube", em referências ao mais famoso líder do cangaço brasileiro, convocando imaginário do popular nordestino. As "vestimentas despojadas" (aparece muitas vezes sem camisa), o "sotaque nordestino”, o cenário doméstico, antes um "quarto de solteiro, modesto e bagunçado"; hoje o apartamento com "móveis brancos planejados" (FROTA, 2019), constituem marcações importantes de consagração. Em seu canal ${ }^{3}$, Whindersson aparece num espaço doméstico e íntimo (do quarto de casa ou do quarto de hotel) e olha para a câmera como estratégia de conversação com seus seguidores.

\footnotetext{
${ }^{3}$ https://www.youtube.com/user/whinderssonnunes, com 37,3 milhões de inscritos em 06.11.2019.
} 


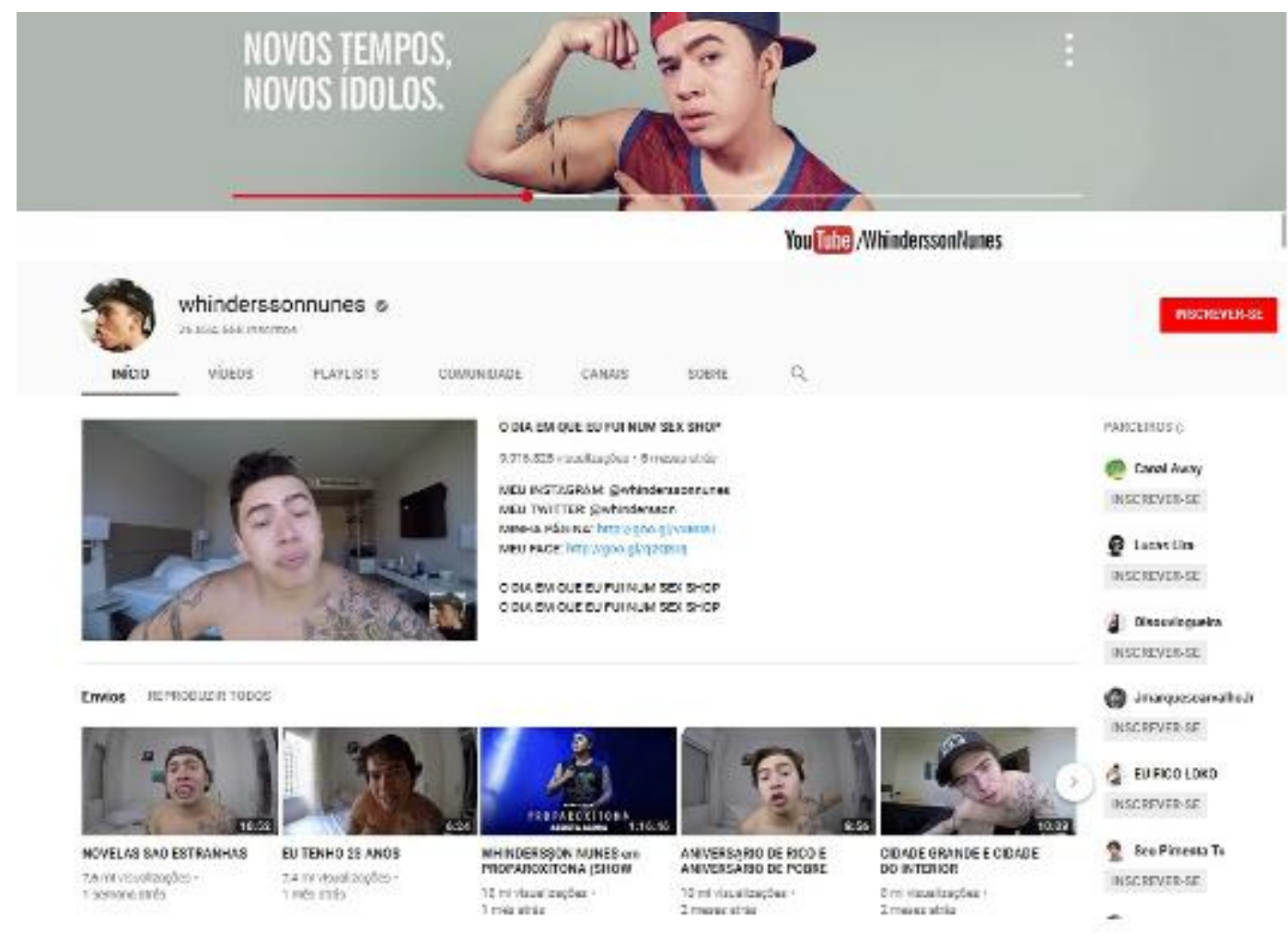

Figura 4 - Print da página principal do canal whinderssonnunes no YouTube (2018) Fonte: https://www.youtube.com/user/whinderssonnunes

No âmbito acadêmico, as formulações se sofisticam teoricamente quando autores (LANA, 2015; SACRAMENTO; BORGES, 2017) aproximam esses modos de exibição de si ao conceito de televisão da intimidade, cunhado ainda na década de 1990 por Dominique Méhl (1997). O termo é usado para caracterizar a exibição da intimidade, do testemunho, das experiências pessoais que marcam o endereçamento dos reality shows, talk shows, dos programas de auditório e noticiários televisivos. "Potencializada pelo seu caráter amador, a televisão da intimidade, no vlog, realça a experiência de pessoas comuns" (LANA, 2015, p. 8). O lugar de celebrização se ampara pela narrativa seriada e periódica, com forte referência ao real "porque pessoal e íntima" (SACRAMENTO; BORGES, 2017). O valor de autenticidade é forjado pelas gravações amadoras, cenários de ambientes domésticos, edição abrupta, modos de fala coloquial, pelo testemunho, pela exposição das experiências pessoais, por uma narrativa episódica que, mesmo disposta a ser consumida por uma sequência pretendida pelo usuário, se articula, constitui um tempo periódico, serial e repetitivo.

Sacramento e Borges (2017) refletem sobre como as lógicas e formatos televisivos operam nos modos de expressão de si no YouTube e propõem a noção de "televisualidade midiática" como um argumento conceitual para o fato de "as estratégias, gêneros e formatos 
televisivos não se restringirem ao meio, mas terem vida social, o que, numa sociedade midiatizada, significa participar de variados processos e práticas culturais" (SACRAMENTO; BORGES, 2017, p.2), em especial, aquelas relacionadas ao YouTube.

Assim, entendemos que os discursos sobre o audiovisual que constituíram os vlogs e hoje atravessam o YouTube posicionam a TV enquanto importante matriz midiática na constituição desse "novo" sensorium, o qual, obviamente, não é um movimento de mera influência de um meio sobre outro, mas de trânsito, atravessamentos e disputas. Compreendemos as relações entre televisão e YouTube enquanto rede de fluxos que ressignificam conjuntamente modos de produção, lógicas corporativas e hábitos de consumo. Nesse quesito, concordamos com Van Dijck (2013) quando ela observa a adoção de lógicas televisivas pelo YouTube, mas também chama atenção para a incorporação da forma visual dos vídeos presentes na plataforma pela TV.

\section{CONSIDERAÇÕES E NOVOS DESAFIOS}

Reconhecemos que os aspectos técnicos são indissociáveis ao YouTube. Fibras ópticas, software, hardware, sinais de satélite, algoritmos, entre outros, possibilitam sua existência material. O percurso aqui descrito, contudo, buscou acentuar o sentido de tecnicidade (MARTIN-BARBERO, 2008) como lugar teórico para pensar tecnologia, discursos e seus usos. Nosso esforço foi historicizar essa forma audiovisual a partir dos seus modos de acepção em disputa, que atravessam lógicas de produção, recepção e formatos. Os resultados deste estudo apontam para os contornos de uma experiência audiovisual não mais simplesmente definida pela televisão, mas que ainda tem nela uma dimensão matricial.

E se a TV parece ainda explicar lógicas de produção, circulação e consumo na internet, é também explicada por elas. Não falamos de um tempo passado que influencia o presente, mas de temporalidades que se articulam em um fluxo de sentidos, que atravessa não apenas a TV, os vlogs e o YouTube, mas também o rádio, a indústria da música, o cinema, o jornalismo etc. Se, neste momento, acionamos matrizes televisivas - valores de periodicidade, novidade, intimidade e instantaneidade, o sentido de testemunho, a serialidade, a ideia de canal, de programa e vinhetas - para refletir sobre o vlog e o YouTube, também identificamos pistas sobre processos de descontinuidades e distinções. Os sentidos de conectividade e interatividade, as lógicas e dinâmicas algorítmicas parece-nos chaves importantes para avançar em reflexões futuras. Não se trata, portanto, de afirmar a TV na Internet, mas de 
posicionar a TV como matriz cultural e midiática, como dimensão legítima de compreensão das transformações do audiovisual na contemporaneidade. O desafio agora é avançar na investigação das dimensões de distinção e ruptura que constituem essa "nova" cultura audiovisual.

\section{REFERÊNCIAS}

BARRETO, Juliano. Nova mania leva vídeo a diários virtuais. Folha de São Paulo. Informática, 24/11/2004. Disponível em: <http://www1.folha.uol.com.br/fsp/informat/fr2411200401.htm>. Acesso em $06 / 01 / 2018$;

BENJAMIN, Walter. A obra de arte na era de sua reprodutibilidade técnica. In: BENJAMIN, Walter. Obras Escolhidas. Magia e Técnica, Arte e Política, São Paulo: Brasiliense, $3^{\text {a }}$ edição, 1987;

BLOGUE passa a utilizar sons para atrair internautas. Folha de São Paulo. 24/11/2004. Disponível em: <http://www1.folha.uol.com.br/folha/informatica/ult124u17526.shtml>. Acesso em: 11/02/2018;

BOXER, Sara. Depois dos blogueiros, os vlogueiros. O Globo. Informática etc. 01/08/2005. Reprodução The New York Times. Acervo O Globo;

BURGESS, Jean; GREEN, Joshua. YouTube e a revolução digital: como o maior fenômeno da cultura participativa transformou a mídia e a sociedade. São Paulo: Aleph, 2009;

CELESTINO, Helena. Vídeos do YouTube, coqueluche na internet. O Globo. 23/07/2006, Matutina, Economia, p. 83. Acervo O Globo;

CONHEÇA alguns blogues com vídeo. Folha de São Paulo. 24/11/2004. Disponível em: <http://www1.folha.uol.com.br/folha/informatica/ult124u17524.shtml>. Acesso em: 08/02/2018;

EM 2006, o recém-nascido e ‘limitado’ YouTube foi capa de VEJA. Blog ReVeja. Veja. 15/02/2018.

$<$ https://veja.abril.com.br/blog/reveja/em-2006-o-recem-nascido-e-limitado-youtube-foi-capa-de-veja/> Acesso em 22/02/2018;

FELINTO, Erick. Em Busca do Tempo Perdido: O Sequestro da História na Cibercultura e os Desafios da Teoria da Mídia. Revista Matrizes, USP, vol 4, nº 2, 2011;

FISCHBERG, Josy. Fala que eu te assisto. Revista O Globo. 12 de julho de 2015, p. 22-30. Acervo O Globo;

FOUCAULT, Michael. A arqueologia do saber. Rio de Janeiro: Forense Universitária, 2013;

FROTA, Etel. Inscreva-se, curta e acredite. Folha de São Paulo. 08/02/2019. Disponível em $<$ http://temas.fo-lha.uol.com.br/influenciadores-digitais/as-estrelas/folha-acompanha-whinderssonyoutuber-que-saiu-do-interior-do-piaui-para-a-pole-position-nacional.shtml>. Acesso em: 05/11/2019;

GROSSMAN, Lev. You - Yes, You - Are TIME's Person of the Year. Time. 25/12/2006. Disponível em: <http://content.time.com/time/specials/packages/0,28757,2019341,00.html>. Acesso em: 05/02/2018;

GUTMANN, Juliana Freire. Sobre performance e historicidade: uma abordagem estética e cultural da MTV Brasil . E-compos, Brasília, v.18, n.2, 2015; 
JENKINS, Henry. Cultura da Convergência. São Paulo: Aleph, 2009;

LARA, Matheus. Veteranos do YouTube se 'reciclam' para acompanhar evolução do público. Estado de São Paulo. 13/11/2016. Disponível em: http://emais.estadao.com.br/noticias/gente,veteranos-do-youtube-se-reciclam-para-acompanharevolucao-do-publico,10000087853>. Acesso em 04/02/2018;

LANA, Lígia. "É muito íntimo": vlogs femininos, fama e linguagem televisiva no YouTube. XXIV Encontro Anual da COMPÓS. Disponível em:< http://www.compos.org.br/biblioteca/compos-2015057ec4ee-c5a0-46f5-9425-bd6053922836_2870.pdf>. Acesso em: 02/02/2018;

LOPES, M. I. V. Mediação e recepção. Algumas conexões teóricas e metodológicas nos estudos latino-americanos de comunicação. Matrizes, São Paulo, v. 8, n. 1, p. 65-80, jan./jun. 2014;

MACHADO, André; MONTEIRO, ELIAS. E o vídeo vem aí. Olê, olê, olá. O Globo. Informática etc. 15/11/2004. Acervo O Globo;

MANS, Matheus; CAPELAS, Bruno. Escolas ensinam como se tornar um youtuber. O Estado de São Paulo. Economia. Link. 11/12/2016, p. 33. Acervo: O Estado de São Paulo;

MARTÍN-BARBERO, Jesús. Dos meios às mediações: comunicação, cultura e hegemonia. $5^{\mathrm{a}}$ ed. Rio de Janeiro: Editora UFRJ, 2008;

MARTINS, Rodrigo. Seu blog fica mais legal com vídeos. O Estado de São Paulo. Informática. 17/04/2006. p. 46;

MÉHL, D. La télévision de l'intimité. Paris: Seuil, 1996;

MONTAÑO, Sonia. A construção do usuário na cultura audiovisual do YouTube. XXV Encontro Anual da Compós. Universidade Federal de Góias, 2016;

MONTEIRO, Elis. Te vi no Youtube. O Globo. Segundo Caderno. p.1. 02 de setembro de 2006. Acervo O Globo;

MONZILLO, Marina. A terceira geração dos blogs. Isto É Gente. Internet. 17/05/2004. Disponível em: <https://www.terra.com.br/istoegente/249/diversao_arte/internet.htm>. Acesso em: 07/02/2018;

OS 10 youtubers que mais ganham dinheiro. O Globo, Economia. S/d. Disponível em <https://oglobo.globo.com/economia/os-10-youtubers-que-mais-ganham-dinheiro-20597627>. Acesso em: 14/02/2018;

PREÇOS baixos estimulam criação de blogues com vídeos. Folha de São Paulo. 24/11/2004. Disponível em: <http://www1.folha.uol.com.br/folha/informatica/ult124u17525.shtml>. Acesso em 11/02/2018;

PONIEWOZIK, James. The Year of Them. Time. 19/12/2007. Disponível em: <http://content.time.com/time/specials/2007/personoftheyear/article/0,28804,1690753_1695417_1695 397,00.html>. Acesso em 04/11/2019;

RIBEIRO, Ana Paula Goulart; MARTINS, Bruno Guimarães; ANTUNES, Elton. Linguagem, sentido e contexto: considerações sobre comunicação e história. Revista Famecos, Porto Alegre, v. 24, no 3, p. 27047, setembro, outubro, novembro e dezembro de 2017; 
RIGA, Matheus. Whindersson Nunes defende pausa para criar: "Fundamental". Terra. 12/09/2019. Disponível em: < https://www.terra.com.br/noticias/tecnologia/inovacao/whindersson-nunes-defendepausa-para-criar-fundamental,ee0790e420ef1264ed0755209fbdb44ftljewt5g.html>. Acesso em 04/11/2019;

ROCHA, Camilo. A televisão dos nossos tempos. O Estado de São Paulo. link. 26/10/2014. Disponível em: <http://link.estadao.com.br/blogs/homem-objeto/a-televisao-dos-nossos-tempos/>. Acesso em 10/12/2018;

SACRAMENTO, Igor; BORGES, W.C.. A televisualidade midiatizada do testemunho: a dismorfia corporal num canal do YouTube. In: XXVI Encontro Nacional da Compós, Faculdade Cásper Líbero, São Paulo, 2017;

SILVA, Fernanda.; GUTMANN, Juliana. De Hebe ao Encontro, o que se disputa? Matrizes do talk show nacional. Matrizes (ONLINE), v. 12, p. 235-257, 2018;

VAN DIJCK, José. A critical history of social media. Oxford University Press, 2013;

WHINDERSSON Nunes e outros: as 5 estrelas do YouTube com mais seguidores no mundo. BBC Brasil. 20/01/2018. Disponível em: <http://www.bbc.com/portuguese/salasocial-42740339>. Acesso em 12/02/2018;

WILLIAMS, Raymond. Televisão: tecnologia e forma cultural. $1^{\text {a }}$ ed. São Paulo: Boitempo; Belo Horizonte, MG: PUCMinas, 2016;

WILLIAMS, Raymond. Palavras-chave: um vocabulário de cultura e sociedade. São Paulo: Boitempo, 2007 [1983];

YOUTUBE comemora sucesso da ferramenta Content ID. Terra. 7/10/2009. Disponível em: $<$ https://www.terra.com.br/noticias/youtube-comemora-sucesso-da-ferramenta-contentid,009de9f6e80ea310VgnCLD200000bbcceb0aRCRD.html>. Acesso em 20/07/2020.

\section{Vídeos:}

JAWED. Me at the zoo. YouTube. 23/04/2005 (18'). Disponível em: < https://youtu.be/jNQXAC9IVRw >. Acesso em 15/02/2018;

TRUEBUJAH. Primeiro Video da Serie Nós \& Nóis. YouTube. 02/02/ 2007 (3' 9"). Disponível em: <https://youtu.be/4_UBOh3J12Q>. Acesso em 05/02/2018. 


\section{Juliana Freire Gutmann}

Professora do Departamento de Comunicação e do Programa de Pós-Graduação em Comunicação e Cultura Contemporâneas da Universidade Federal da Bahia. Líder do Grupo de Pesquisa Cultura Audiovisual, Historicidades e Sensibilidades - CHAOS, UFBA. Pesquisadora do Centro de Pesquisa em Estudos Culturais e Transformações na Comunicação - TRACC, UFBA.

Fernanda Gonçalves Caldas

Mestre em Comunicação e Cultura Contemporâneas pela Universidade Federal da Bahia. Pesquisadora Associada do Centro de Pesquisa em Estudos Culturas e Transformações na Comunicação - TRACC,

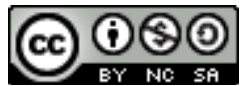

Esta obra está licenciada com uma Licença

Creative Commons Atribuição-NãoComercial-CompartilhaIgual 4.0 Internacional 